\title{
Synergistic effect of sertraline and disulfiram against multidrug resistant bacteria as a new alternative to drug repositioning
}

\author{
Marissa Bolson Serafin ${ }^{1}$, Angelita Bottega ${ }^{1}$, Vitória Segabinazzi Foletto², Taciéli Fagundes da Rosa ${ }^{1}$, \\ Roberta Filipini Rampelotto ${ }^{1}$, Fernanda Aguirre Carvalhoํ, Rosmari Hörner ${ }^{\circledR 3^{*}}$
}

\begin{abstract}
${ }^{1}$ Universidade Federal de Santa Maria, Programa de Pós-graduacão em Ciências Farmacêuticas, Santa Maria, RS, Brazil, ${ }^{2}$ Universidade Federal de Santa Maria, Santa Maria, RS, Brazil, ${ }^{3}$ Universidade Federal de Santa Maria, Departamento de Análises Clínicas e Toxicológicas, Santa Maria, RS, Brazil
\end{abstract}

\begin{abstract}
The repositioning of approved drugs is atopic of interest for the academy and the pharmaceutical industry. The synergistic combination of these drugs can be successful in the treatment of infections caused by resistant bacteria. This study aimed to assess the in vitro synergistic antibacterial activity of sertraline and disulfiram and their interaction with ciprofloxacin and sulfamethoxazole/trimethoprim. We determined the minimum inhibitory concentration, the minimum bactericidal concentration and the fractional inhibitory concentration index. Eighteen bacterial strains were used, being nine American Type Culture Collection reference strains and nine multidrug resistant clinical isolates. Synergy was detected between sertraline and disulfiram against a strain of Staphylococcus aureusATCC 25923 and a clinical isolate of S. aureus. When associated to sulfamethoxazole/trimethoprim and ciprofloxacin, sertraline and disulfiram showed eight synergistic events, which occurred against three different standard strains and two multidrug resistant clinical isolates. When the minimum bactericidal concentration was determined, the bactericidal activity of sertraline was enhanced with disulfiram. Our results suggest that these drugs, widely used to treat depression and chronic alcoholism, have antibacterial potential individually, in association, and combined with antimicrobials, what makes their repositioning a promising therapeutic alternative for the effective treatment of infections caused by multidrug resistant bacteria.
\end{abstract}

Keywords: Sertraline. Disulfiram.Antimicrobial activity. Drug synergism. Drug repositioning.

\section{INTRODUCTION}

The indiscriminate use of antimicrobials in clinical therapy has triggered the emergence of multidrug resistant bacteria (MDR) (Dos Santos, La Rocca, Hörner, 2016), what represents a serious problem for public health worldwide since the therapeutic alternatives for treatments have become limited (Franco, Menezes, Cabral, 2015).

Although there is an increasing need for active compounds against MDR bacteria, research for new drugs has not evolved in line with the demand, and alternative measures are necessary for the control of infectious diseases (Grillo etal., 2014). Therefore, new therapies

\footnotetext{
*Correspondence: R.Hörner. Departamento de Análises Clínicas e Toxicológicas, Universidade Federal de Santa Maria - UFSM. Avenida Roraima, 1000 - Cidade Universitária, Camobi, CEP: 97105-900 - Santa Maria - RS, Brazil. Phone: 5555 3220-8751. Mobile Phone: 55 99111-9691. E-mail: rosmari.ufsm@gmail.com
}

can emerge through drug repositioning with drugs that are already used clinically and whose tests with patients are known (Wiggins et al., 2015). In addition, there can be synergistic combinations between these drugs, contributing to a more effective treatment (Zheng, Sun, Simeonov, 2017).

Ashburn and Thor (2004) defined drug repositioning as the process of finding a new indication for a drug which has already been approved. This method has proved to be the preferred alternative strategy for the fast-moving discovery of drugs, since it is relatively cheaper and represents a minimum risk to patients due to the availability of previous pharmacological, safety and toxicological data (Mehndiratta et al., 2016).

In light of this, repositioning is an attractive approach for studies that investigate the antimicrobial activities of psychotropics, local anaesthetics, tranquilizers, as well as cardiovascular, anti-histaminic and antiinflammatory drugs (Chan et al., 2017; Mandal et al., 
2010; Rampelotto et al., 2018). The combination of drugs has been successfully used to treat MDR bacteria due to the synergistic effect achieved by the aggregation of their different action mechanisms. Thus, a fast identification of therapies to treat acute infections also emerges with the combination of repositioned synergistic drugs, outweighing the problem of weak drug activity when used individually (Zheng, Sun, Simeonov, 2017).

Thus, this study assessed the in vitro antibacterial activity of sertraline and disulfiram, the synergy of their combination and the combination with the antimicrobials ciprofloxacin and sulfamethoxazole/trimethoprim. The tests were performed through the determination of the minimum inhibitory concentration (MIC), minimum bactericidal concentration (MBC), and the assessment of the fractional inhibitory concentration index (FICI).

\section{MATERIAL AND METHODS}

\section{Bacterial strains}

Eighteen bacterial strains were used, including nine American Type Culture Collection (ATCC) reference strains (Staphylococcus aureus ATCC 25923, Staphylococcus aureus ATCC 29213, Enterococcus faecalis ATCC 29212, Micrococcus luteus ATCC 7468, Bacillus cereus ATCC 14579, Escherichia coli ATCC 35218, Escherichia coli ATCC 25922, Klebsiella pneumoniae ATCC 700603 and Pseudomonas aeruginosa ATCC 27853), and nine MDR clinical isolates from patients at Hospital Universitário de Santa Maria (HUSM): four isolates of $S$. aureus, and one isolate of each of the following species: S. warneri, S. haemolyticus, S. epidermidis, P. aeruginosa and $A$. baumannii.

The clinical isolates were identified with the automated system Vitek ${ }^{\circledR} 2$ (bioMérieux, France). For the characterization of MDR bacteria, the guidelines of the Technical Note n. 1/2010 from the Brazilian National Health Surveillance Agency (ANVISA) (Anvisa, 2010) were followed. According to these guidelines, MDR bacteria are microorganisms resistant to different classes of antimicrobials tested in microbiological control tests. The use of these isolates for clinical research was approved by the Research Ethics Committee of Universidade Federal de Santa Maria (UFSM) under the protocol number: 38850614.4.0000.5346.

\section{Drugs used}

Sertraline (Legrand Pharma Indústria Farmacêutica Ltda., Hortolândia, SP, Brazil), disulfiram (Sanofi-Aventis
Farmacêutica Ltda., São Paulo, SP, Brazil), ciprofloxacin (Cimed Indústria de medicamentos Ltda, Pouso Alegre, MG, Brazil) and sulfamethoxazole/trimethoprim (Produtos Roche Químicos e Farmacêuticos S. A., Rio de Janeiro, RJ, Brazil) were tested against all the abovecited strains. To obtain the stock solution of sertraline, ciprofloxacin and sulfamethoxazole/trimethoprim, they were dissolved in absolute methanol, and disulfiram was dissolved in absolute ethanol. The tested concentration for these drugs was $0.5-512 \mu \mathrm{g} \mathrm{mL}^{-1}$. In order to confirm the inexistence of inhibitory activity of solvents, $10 \%$ methanol and ethanol were used in a test performed separately.

\section{Antibacterial and susceptibility tests}

Minimum inhibitory concentration (MIC) determinations MIC was determined through the standard method of broth microdilution according to the Clinical and Laboratory Standards Institute (CLSI, 2012). Tests were run in triplicate, with reports being visually performed after 24 hours of incubation at $35 \pm 2{ }^{\circ} \mathrm{C}$. The bacterial inoculum was prepared in a sterile saline solution, with concentration of bacterial suspension following the $0.5 \mathrm{McF}$ arland scale, which is $1.5 \times 10^{8}$ colony forming units $/ \mathrm{mL}$ (UFC/mL).

\section{Minimum bactericidal concentration (MBC) determinations}

MBC was performed according to the method described in the document M26-A from the National Committee for Clinical Laboratory Standards (NCCLS) (NCCLS, 1999), with adaptations. After the visual reading of MIC, approximately $10 \mu \mathrm{L}$ of the content from the pits where there was no visible bacterial growth were removed, as well as from the last pit, with visible bacterial growth. This volume was stocked in petri dishes with Mueller-Hinton agar, and incubated at $35 \pm 2{ }^{\circ} \mathrm{C}$ for 48 h. After incubation, $\mathrm{MBC}$ was determined as the smallest concentration in which no microorganism growth was observed.

\section{Fractioned inhibitory concentration index ( $\mathrm{FICI})$ determinations}

Synergism analysis of the two drugs was obtained by calculating the fractioned inhibitory concentration index (FICI), whose interpretation can be classified as "synergistic" (FIC $\leq 0,5)$, "non-interactive" (FIC $>0.5$ e $\leq 4.0$ ) and "antagonistic" (FIC > 4.0) (Konaté et al., 2012; Odds, 2003). 


\section{RESULTS AND DISCUSSION}

MIC and FICI values obtained can be seen in Table I. Results show that disulfiram was particularly more active against standard Gram-positive strains, whereas sertraline showed activity against both standard Gram-positive and Gram-negative strains. When their activity was tested against clinical isolates, sertraline showed strong activity against five isolates of Staphylococcus $\left(\mathrm{MIC}=8 \mu \mathrm{g} \cdot \mathrm{mL}^{-1}\right.$ ). When combined, sertraline and disulfiram showed a synergistic effect against Staphylococcus aureus ATCC 25923 and the isolate $S$. aureus $\mathrm{MDR}(1)\left(\mathrm{MIC}=4 \mu \mathrm{g} \mathrm{mL}{ }^{-1}\right.$; $\mathrm{FICI}=0$ 5).

Regarding the interaction of these two drugs with conventional antimicrobials, the synergy of sertraline and disulfiram with sulfamethoxazole/trimethoprim was observed against the strain of E. coli ATCC 35218. When associated to ciprofloxacin, they showed synergy against $B$. cereus.Also, the combination of ciprofloxacin with disulfiram was effective against the strain of M. luteus and the clinical isolate $A$. baumannii, where as the interaction of disulfiram with sulfamethoxazole/trimethoprim showed synergy against the isolates $P$. aeruginos $a$ and A. baumannii.

Munoz-Bellido, Munoz-Criado and GarcíaRodríguez (2000) assessed the antibacterial activity of sertraline in different clinical isolates from patients at Hospital Universitario de Salamanca, Spain. The values of MIC 90 obtained against $S$. aureus $\left(\mathrm{MIC}=16 \mu \mathrm{g} \cdot \mathrm{mL}^{-1}\right)$ and $S$. epidermidis $\left(\mathrm{MIC}=16 \mu \mathrm{g} . \mathrm{mL}^{-1}\right)$, were similar to the ones found in this study, however, the values of A. baumanii (MIC $=64 \mu \mathrm{g} \cdot \mathrm{mL}^{-1}$ ) and $E$. coli $\left(\mathrm{MIC}=128 \mu \mathrm{g} \cdot \mathrm{mL}^{-1}\right)$ were higher than those found in our study.

Philips et al. (1991) obtained MIC $=1,33 \mu \mathrm{g} \cdot \mathrm{mL}^{-1}$ for all the investigated isolates while investigating the in vitro activity of disulfiram against $S$. aureus in Valhalla, New York. In the present study, we found MIC values higher than those reported by that research group. This fact may be related to the differences of the raw material used and its dissolution, and the different clinical isolates. However, when associating sertraline and disulfiram, we observed

TABLE I - Minimum inhibitory concentrations (MIC) of the sertraline, disulfiram, sulfamethoxazole/trimethoprim and ciprofloxacin, alone and in combination against standard strains and clinical isolates

\begin{tabular}{|c|c|c|c|c|c|c|c|c|c|c|c|c|c|c|}
\hline Bacterial strain & & & & & & & $\operatorname{MIC}(\mu$ & g $\left.\mathbf{~ m L}^{-1}\right)$ & & & & & & \\
\hline Standard strains ATCC & SER & DSF & $\begin{array}{c}\text { SER } \\
+ \text { DSF } \\
\end{array}$ & FICI & SUT* & $\begin{array}{l}\text { SUT* } \\
+ \text { SER }\end{array}$ & FICI & $\begin{array}{l}\text { SUT* } \\
+ \text { DSF }\end{array}$ & FICI & CIP & $\begin{array}{c}\text { CIP } \\
+ \text { SER }\end{array}$ & FICI & $\begin{array}{c}\text { CIP } \\
+ \text { DSF }\end{array}$ & FICI \\
\hline Staphylococcus aureus ATCC 29213 & 32 & $>512$ & 32 & - & 1 & 1 & 1.03 & 1 & - & 4 & 4 & 1.125 & 4 & - \\
\hline Staphylococcus aureus ATCC 25923 & 16 & 16 & 4 & 0.5 & 256 & 16 & 1.06 & 16 & 1.06 & 256 & 16 & 1.06 & 16 & 1.06 \\
\hline Enterococcus faecalis ATCC 29212 & 16 & 16 & 8 & 1 & 1 & 0,5 & 0,53 & 0,5 & 0,53 & 1 & 0,5 & 0,53 & 0,5 & 0,53 \\
\hline Micrococcus luteus ATCC 7468 & 16 & 32 & 8 & 0.75 & 256 & 32 & 2.125 & 32 & 1.125 & 64 & 8 & 0.625 & 4 & 0.18 \\
\hline Bacillus cereus ATCC 14579 & 32 & 8 & 4 & 0,62 & 32 & 32 & 2 & 4 & 0.625 & 2 & 0,25 & 0.13 & 0,25 & 0.15 \\
\hline Escherichia coli ATCC 35218 & 32 & 256 & 16 & 0.56 & 8 & 1 & 0.15 & 1 & 0.12 & 1 & 2 & 2.06 & 2 & 2.00 \\
\hline Escherichia coli ATCC 25922 & 32 & $>512$ & 32 & - & 1 & 0,5 & 0.51 & 0,5 & - & 0,25 & 0,25 & 1,0 & 0,25 & - \\
\hline Klebsiella pneumoniae ATCC 700603 & 16 & $>512$ & 32 & - & 4 & 4 & 1.25 & 16 & - & 0,5 & 0,25 & 0.51 & 0,25 & - \\
\hline Pseudomonas aeruginosa ATCC 27853 & $>512$ & $>512$ & $>512$ & - & 256 & 128 & - & 64 & - & 1 & 0,25 & - & 0,25 & - \\
\hline \multicolumn{15}{|l|}{ Clinical isolates } \\
\hline Staphylococcus aureus MDR (1) & 16 & 16 & 4 & 0.5 & 256 & 16 & 1.06 & 32 & 2.125 & 64 & 8 & 0.625 & 32 & 2.5 \\
\hline Staphylococcus aureus MDR (2) & 16 & 16 & 16 & 2 & 256 & 16 & 1.06 & 16 & 1.06 & 64 & 32 & 2.5 & 16 & 1.25 \\
\hline Staphylococcus aureus MDR (3) & 8 & 4 & 4 & 1.5 & 128 & 8 & 1.06 & 8 & 2.06 & 128 & 16 & 2.06 & 16 & 2.12 \\
\hline Staphylococcus aureus MDR (4) & 8 & 16 & 16 & 3 & 512 & 16 & 2.03 & 16 & 1,03 & 256 & 16 & 2.06 & 16 & 1,06 \\
\hline Staphylococcus warneri MDR & 8 & 16 & 4 & 0.75 & 512 & 512 & 8 & 256 & 1.01 & 512 & 16 & 1.03 & 16 & 2.03 \\
\hline Staphylococcus haemolyticus MDR & 8 & 8 & 4 & 1 & 256 & 16 & 2.06 & 16 & 2.06 & 128 & 16 & 2.12 & 16 & 2.12 \\
\hline Staphylococcus epidermidis MDR & 8 & 16 & 8 & 1.5 & 16 & 16 & 3 & 8 & 1 & 2 & 2 & 1.25 & 2 & 1.12 \\
\hline Pseudomonas aeruginosa MDR & 16 & 512 & 32 & 2.06 & 128 & 32 & 2.25 & 32 & 0.31 & 1 & 1 & 1.06 & 1 & 1 \\
\hline Acinetobacter baumannii oxa 23 MDR & 16 & 128 & 16 & 1.125 & 256 & 32 & 2.12 & 16 & 0,18 & 32 & 32 & 3 & 8 & 0,31 \\
\hline
\end{tabular}

SER, sertraline; DSF, disulfiram; SER+ DSF, combination of sertraline and disulfiram; SUT, sulfamethoxazole/trimethoprim; SUT+ SER, combination of sulfamethoxazole/trimethoprim and sertraline; SUT +DSF, combination of sulfamethoxazole/trimethoprim and disulfiram; CIP, ciprofloxacin; CIP+SER, combination of ciprofloxacin and sertraline; CIP+DSF, combination of ciprofloxacin and disulfiram; FICI, Fractional Inhibitory Concentration Index; (-), result without determination; MDR, multidrug-resistant bacteria. *,5 times the concentration of trimethoprim. 
that such combination was able to inhibit the growth of the MDRS. aureus, with FICI $=0.5$, what characterizes a synergistic effect between these drugs.

Studies that assess the synergistic antibacterial activity of potential candidates for drug repositioning are already being explored, such as the one developed by Chan et al. (2017) in Malaysia. These researchers have assessed the synergistic antibacterial activity of the non-steroidal anti-inflammatory drugs cefuroxime and chloramphenicol against methicillin-resistant and methicillin-susceptible $S$. aureus; however, MICs were evaluated in $\mathrm{mg} \cdot \mathrm{mL}^{-1}$, and their concentrations were around one thousand times higher than the ones in the current study.

The antibacterial mechanisms of action of sertraline and disulfiram have not yet been established. However, Munoz-Bellido, Munoz-Criado, and García-Rodríguez have suggested that the action of sertraline occurs through the inhibition of efflux pumps, since it is a consensus that this drug acts in human cells as an inhibitor of these pumps
(Munoz-Bellido, Munoz-Criado, Garcìa-Rodrìguez, 2000).

Disulfiram, on the other hand, shows several mechanisms capable of inhibiting bacterial growth. Its main metabolite is diethyldithiocarbamate (DDTC). This drug is probably metabolized by the bacteria in order to form DDTC, which has antibacterial effects (Horita et al., 2009; Horita et al., 2012; Takii et al., 2012). In addition, Cvek (2013) has observed that disulfiram is able to exert proteolytic activity through ion chelation, what may cause bacterial inhibition.

The MBC determination of sertraline and disulfiram is described in Table II. Through these data, we can infer that sertraline individually showed bactericidal activity against most tested strains, whereas disulfiram did not exert this activity. However, when we associated these drugs, the activity of sertraline was intensified, especially against Staphylococcus aureus ATCC 25923, Enterococcus faecalis ATCC 29212, Escherichia coli ATCC 35218 and Bacillus cereus ATCC 14579. As for

TABLE II - Minimum bactericide concentrations (MBC) of the sertraline and the disulfiram, sulfamethoxazole/trimethoprim and ciprofloxacin, alone and in combination against standard strains and clinical isolates

\begin{tabular}{|c|c|c|c|c|c|c|c|c|c|}
\hline \multirow{2}{*}{$\frac{\text { Bacterial strain }}{\text { Standard strains ATCC }}$} & \multicolumn{9}{|c|}{$\operatorname{MBC}\left(\mu \mathrm{g} \mathrm{mL}^{-1}\right)$} \\
\hline & SER & DSF & $\begin{array}{c}\text { SER } \\
+ \text { DSF }\end{array}$ & SUT* & $\begin{array}{l}\text { SUT* }^{*} \\
+ \text { SER }\end{array}$ & $\begin{array}{l}\text { SUT* } \\
+ \text { DSF }\end{array}$ & CIP & $\begin{array}{c}\text { CIP } \\
+ \text { SER } \\
\end{array}$ & $\begin{array}{r}\text { CIP } \\
+ \text { DSF } \\
\end{array}$ \\
\hline Staphylococcus aureus ATCC 25923 & 32 & $>512$ & 16 & $>512$ & 256 & $>512$ & $>512$ & $>512$ & $>512$ \\
\hline Enterococcus faecalis ATCC 29212 & 32 & $>512$ & 16 & $>512$ & 128 & $>512$ & $>512$ & $>512$ & $>512$ \\
\hline Escherichia coli ATCC 35218 & 256 & $>512$ & 32 & $>512$ & $>512$ & $>512$ & $>512$ & 128 & $>512$ \\
\hline Escherichia coli ATCC 25922 & 64 & $>512$ & 64 & $>512$ & 128 & $>512$ & 2 & 2 & 2 \\
\hline Klebsiella pneumoniae ATCC 700603 & 32 & $>512$ & 64 & $>512$ & 128 & $>512$ & 1 & 1 & 1 \\
\hline Pseudomonas aeruginosa ATCC 27853 & $>512$ & $>512$ & $>512$ & 256 & 256 & $>512$ & 1 & 1 & 1 \\
\hline Staphylococcus aureus MDR (3) & 32 & $>512$ & 32 & $>512$ & 128 & $>512$ & 128 & 128 & 128 \\
\hline Staphylococcus aureus MDR (4) & 128 & $>512$ & 32 & $>512$ & 256 & $>512$ & $>512$ & 256 & $>512$ \\
\hline Staphylococcus warneri MDR & $>512$ & $>512$ & 8 & $>512$ & $>512$ & $>512$ & $>512$ & $>512$ & $>512$ \\
\hline Staphylococcus haemolyticus MDR & 64 & $>512$ & 16 & $>512$ & 128 & $>512$ & $>512$ & 128 & $>512$ \\
\hline Staphylococcus epidermidis MDR & 16 & $>512$ & 32 & $>512$ & 64 & 512 & 2 & 2 & 2 \\
\hline Pseudomonas aeruginosa MDR & $>512$ & $>512$ & $>512$ & 128 & 512 & $>512$ & 512 & 512 & 512 \\
\hline Acinetobacter baumanni oxa 23 MDR & 32 & $>512$ & 16 & $>512$ & 64 & $>512$ & $>512$ & 64 & 512 \\
\hline
\end{tabular}

SER, sertraline; DSF, sisulfiram; SER+ DSF, combination of sertraline and disulfiram; SUT, sulfamethoxazole/trimethoprim; SUT+ SER, combination of sulfamethoxazole/trimethoprim and sertraline; SUT +DSF, combination of sulfamethoxazole/trimethoprim and disulfiram; CIP, ciprofloxacin; CIP+SER, combination of ciprofloxacin and sertraline; CIP+DSF, combination of ciprofloxacin and disulfiram; (-), result without determination. *,5 times the concentration of trimethoprim. 
the clinical isolates, this activity was evidenced mainly in S. warneri $\left(\mathrm{MBC}=8 \mu \mathrm{g} \cdot \mathrm{mL}^{-1}\right)$.

In the present study, sertraline and disulfiram showed a synergistic antibacterial activity against specific reference standard strains and MDR clinical isolates tested, and their interactions with sulfamethoxazole/ trimethoprim and ciprofloxacin also showed to be synergistic. These results allow us to suggest that their repositioning is a promising therapeutic alternative for the effective treatment of multi-resistant bacterial infections. Nevertheless, additional studies about the mechanisms of action involved in these activities are needed for the safe associated use of these drugs.

\section{REFERENCES}

Agência Nacional de Vigilância Sanitária (ANVISA), Nota Técnica nº 1/2010, Brasília, Brasil; 2010.

Ashburn TT, Thor KB. Drug repositioning: identifying and developing new uses for existing drugs. Nat Rev Drug Discov.2004;3(8):673-683.

Chan EWL, Yee ZY, Raja I, Yap JKY. Synergistic effect of non-steroidal anti-inflammatory drugs (NSAIDs) on antibacterial activity of cefuroxime and chloramphenicol against methicillin-resistant Staphylococcus aureus. J Glob Antimicrob Resist.2017;10:70-74.

Clinical and Laboratory Standards Institute. Methods for dilution antimicrobial susceptibility tests for bacteria that grow aerobically. Approved standard M07-A9. Wayne, USA: CLSI; 2012.

Cvek B. Comment on cytotoxic effect of disulfiram/copper on human glioblastoma cell lines and ALDH-positive cancer-stemlike cells. Br J Cancer. 2013;108(4):993.

Dos Santos SO, La Rocca SM , Hörner, R. Colistin resistance in non-fermenting Gram-negative bacilli in a university hospital. Braz J Infect Dis. 2016;20(6):649-650.

Franco JMP, Menezes CDA, Cabral FRF. Resistência bacteriana e o papel do farmacêutico frente ao uso irracional de antimicrobianos: revisão integrativa. Rev Ciên. 2015;3(2):57-65.

Grillo STRS, Gonçalves TG, Campos JJ, Paniágua NC, Teles CBG. Incidência bacteriana e perfil de resistência a antimicrobianos em pacientes pediátricos de um hospital público de Rondônia, Brasil. Rev Ciên Farm Básica Apl. 2013;34:117123.
Horita Y, Takii T, Chiba T, Kuroishi R, Maeda Y, Kurono Y, et al. Synthesis of new sugar derivatives and evaluation of their antibacterial activities against Mycobacterium tuberculosis. Bioorg Med Chem Lett.2009;19(22):6313-6.

Horita Y, Takii T, Kuroishi R, Chiba T, Ogawa K, Kremer $\mathrm{L}$, et al. Synthesis and evaluation of anti-tubercular activity of new dithiocarbamate sugar derivatives. Bioorg Med Chem Lett. 2011;21(3):899-903.

Konaté K, Mavoungou JF, Lepengué AN, Aworet-Samseny RRR, Hilou A, Souza A, et al. Antibacterial activity against $\beta$-lactamase producing Methicillin and AmpicillinresistantsStaphylococcus aureus: Fractional Inhibitory Concentration Index (FICI) determination. Ann Clin Microbiol Antimicrob. 2012;11:1-12.

Mandal A, Sinha C, Kumar Jena A, Ghosh S, Samanta A. An investigation on in vitro and in vivo antimicrobial properties of the antidepressant: amitriptyline hydrochloride. Braz J Microbiol. 2010;41(3):635-45.

Mehndiratta MM, Wadhai SA, Tyagi BK, Gulati NS, Sinha M. Drugrepositioning. IntJ Epilepsy. 2016;3(2):91-94.

Munoz-Bellido JL, Munoz-Criado S, García-Rodríguez JA. Antimicrobial activity of psychotropic drugs Selective serotonin reuptake inhibitors. Int J Antimicrob Agents. 2000;14(3):177-180.

National Committee for Clinical Laboratory Standards. Methods for Determining Bactericidal Activity of antimicrobial agents. Approved GuidelineM26-A. Wayne, USA: NCCLS; 1999.

Odds FC. Synergy, antagonism, and what the chequerboard puts between them. J Antimicrob Chemother. 2003;52(1):1.

Phillips M, Malloy G, Nedunchezian D, Lukrec A, Howard RG. Disulfiram Inhibits the in vitro Growth of Methicillin-Resistant Staphylococcus aureus. Antimicrob Agents Chemother. 1991;35(4):785-787.

Rampelotto RF, Lorenzoni VV, Silva DC, Moraes GA, Serafin MB, Tizotti MK, et al. Synergistic antibacterial effect of statins with the complex \{[1-(4-bromophenyl)-3-phenyltriazene

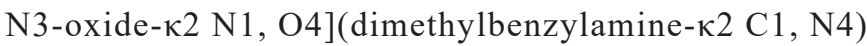
palladium(II)\}. Braz J Pharm Sci. 2018;54(2):e17369. 
Takii T, Horita Y, Kuroishi R, Chiba T, Mori M, Hasegawa $\mathrm{T}$, et al. The potential therapeutic usage of dithiocarbamate sugar derivatives for multi-drug resistant tuberculosis, understanding tuberculosis - new approaches to fighting against drug resistance, Dr. Pere-Joan Cardona (Ed.). InTech, 2012, p. 263-270.

Wiggins HL, Wymant JM, Solfa F, Hiscox SE, Taylor KM, WestwellADet al. Disulfiram-induced cytotoxicity and endolysosomal sequestration of zinc in breast cancer cells. Biochem Pharmacol. 2015;93(3):332-342.
Zheng W, Sun W, Simeonov, A. Drug repurposing screens and synergistic drug-combinations for infectious diseases. $\mathrm{Br} \mathrm{J}$ Pharmacol. 2017;175(2):181-91.

Received for publication on $15^{\text {th }}$ February 2018 Accepted for publication on $17^{\text {th }}$ December 2018 